\title{
Brugada syndrome presenting as incessant polymorphic ventricular tachycardia: a rare cause for a common outcome after cardiac arrest in a middle-aged Asian man
}

\author{
Gopal Chandra Ghosh, ${ }^{1}$ Anoop George Alex, ${ }^{2}$ John Roshan Jacob ${ }^{3}$
}

\begin{abstract}
${ }^{1}$ Department of Cardiology, Christian Medical College and Hospital Vellore, Vellore, Tamil Nadu, India

${ }^{2}$ Christian Medical College and Hospital Vellore, Vellore, Tamil Nadu, India ${ }^{3}$ Department of Electrophysiology, Christian Medical College and Hospital Vellore, Vellore, Tamil Nadu, India
\end{abstract}

\section{Correspondence to} Dr Gopal Chandra Ghosh, gcghosh86@gmail.com

Accepted 1 May 2016
To cite: Ghosh $\mathrm{GC}$, Alex AG, Jacob JR. BMJ Case Rep Published online: [please include Day Month Year] doi:10.1136/bcr-2016215014

\section{DESCRIPTION}

Brugada syndrome $(\mathrm{BrS})$ is a familial disorder and an important though rare cause of sudden cardiac death (SCD). SCD occurs due to ventricular fibrillation (VF), though presentation with incessant polymorphic ventricular tachycardia has also been rarely reported in the literature.

We report a case of BrS presenting with incessant polymorphic ventricular tachycardia that ultimately led to prolonged cerebral ischaemia and hypoxic ischaemic encephalopathy sequelae.

A 34-year-old man, with no previous comorbidities, collapsed suddenly while attending to his morning routine work. He had a history suggestive of presyncopal episodes in the recent past. There was no family history of SCD. He was taken to a nearby hospital within $10-15 \mathrm{~min}$ of collapse, where cardiopulmonary resuscitation (CPR) was initiated. ECG monitor showed polymorphic ventricular tachycardia, so direct current (DC) shock and intravenous magnesium were given. After 20 min of CPR and five cycles of DC shock, the patient reverted to sinus rhythm. Simultaneously, he was intubated and put on ventilatory support. Intravenous amiodarone was started and subsequently discontinued in the medical intensive care unit (ICU) owing to no further arrhythmia. The patient was managed in the medical ICU for the next 3 weeks, with multidisciplinary inputs, as he had developed hypoxic ischaemic encephalopathy sequelae.
ECG taken on arrival (figure 1) showed polymorphic ventricular tachycardia. Another ECG taken a day after resuscitation (figure 2) revealed coved type, $>2 \mathrm{~mm}$ ST segment elevation in leads V1-V3 (Brugada type 1). Based on ECG's, the patient was diagnosed as having a case of BrS. ECG taken after a month showed saddleback type, $>1 \mathrm{~mm}$ ST elevation in leads V1-V3, with biphasic $\mathrm{T}$ wave (Brugada type 2) (figure 3). Echocardiography findings were within normal limits.

$\mathrm{BrS}$ is a familial disease with an autosomal dominant pattern of transmission and incomplete penetrance. It was first described in 1992 as a distinct clinical entity with SCD. ${ }^{1}$ The most severe clinical manifestation of BrS is SCD due to VF. It can also present with recurrent syncope or may remain asymptomatic throughout life. Brugada type 1 and type 2 ECG patterns are more prevalent in Asia as compared with Europe and the USA. ${ }^{2}$ Mean age of developing SCD is $41 \pm 15$ years, though it has been reported from the age of 2 days to 85 years in the literature. ${ }^{3}$ Males have a 5.5 -fold increased risk of SCD as compared to females. ${ }^{3}$ Arrhythmic episodes are predominantly seen from 12:00 to 06:00, and rarely seen during daytime, suggesting the possibility of increased vagal tone in the pathogenesis of BrS. $^{2}$ Prevalence is $5 / 10000$, and it is estimated to be responsible for $20 \%$ of sudden death in patients with structurally normal hearts and $4 \%$ of all sudden deaths. ${ }^{4}$

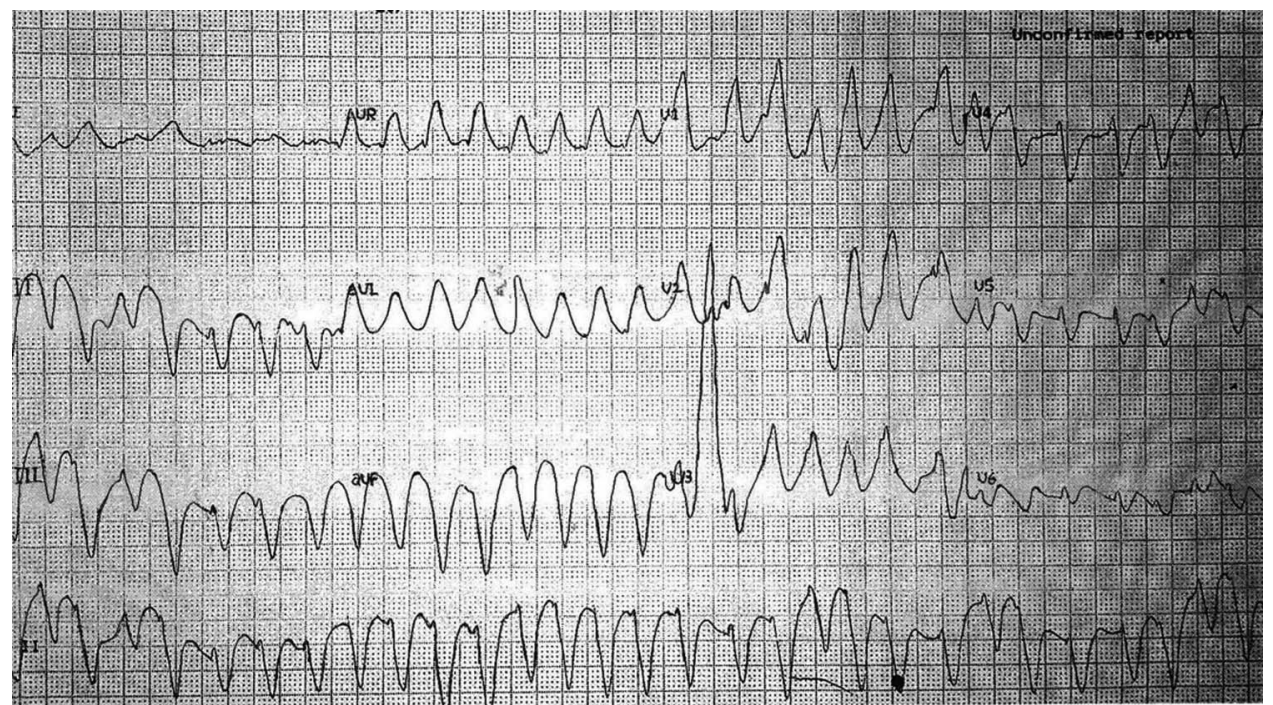

Figure 1 Twelve-lead ECG showing polymorphic ventricular tachycardia. 


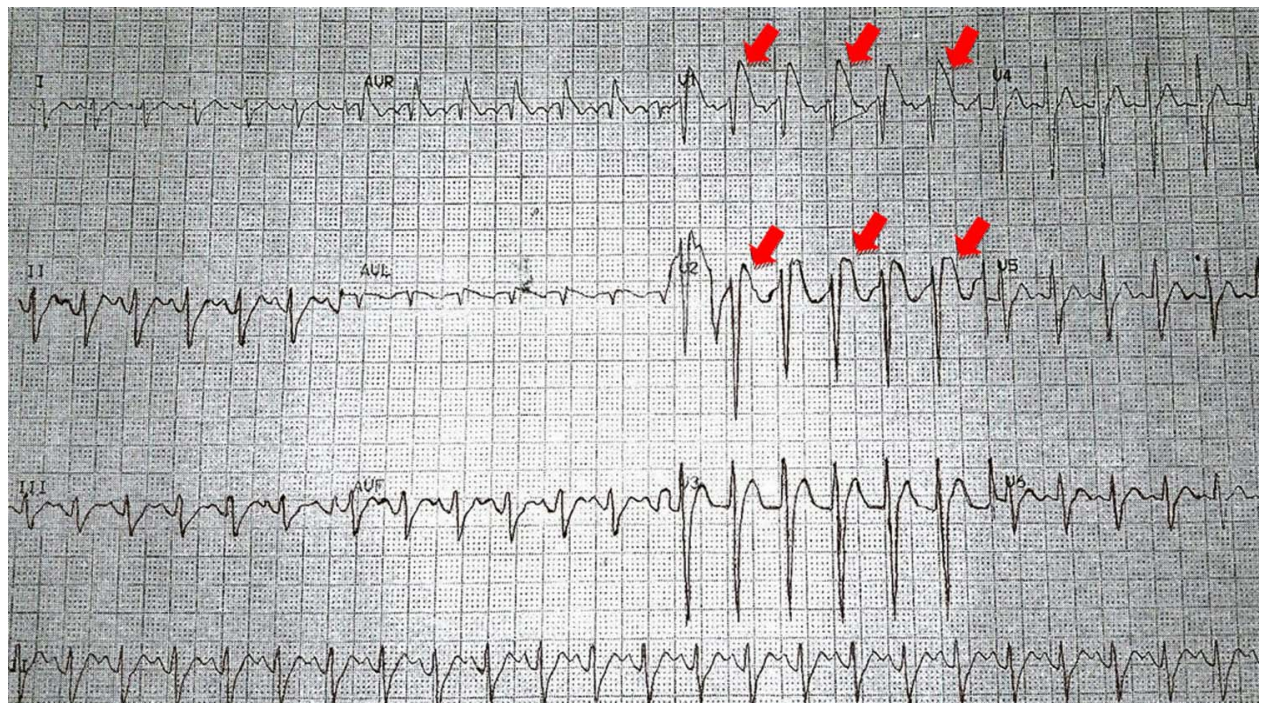

Figure 2 Twelve-lead ECG showing $>2$ mm coved type ST elevation (red arrows) in leads V1-V3.

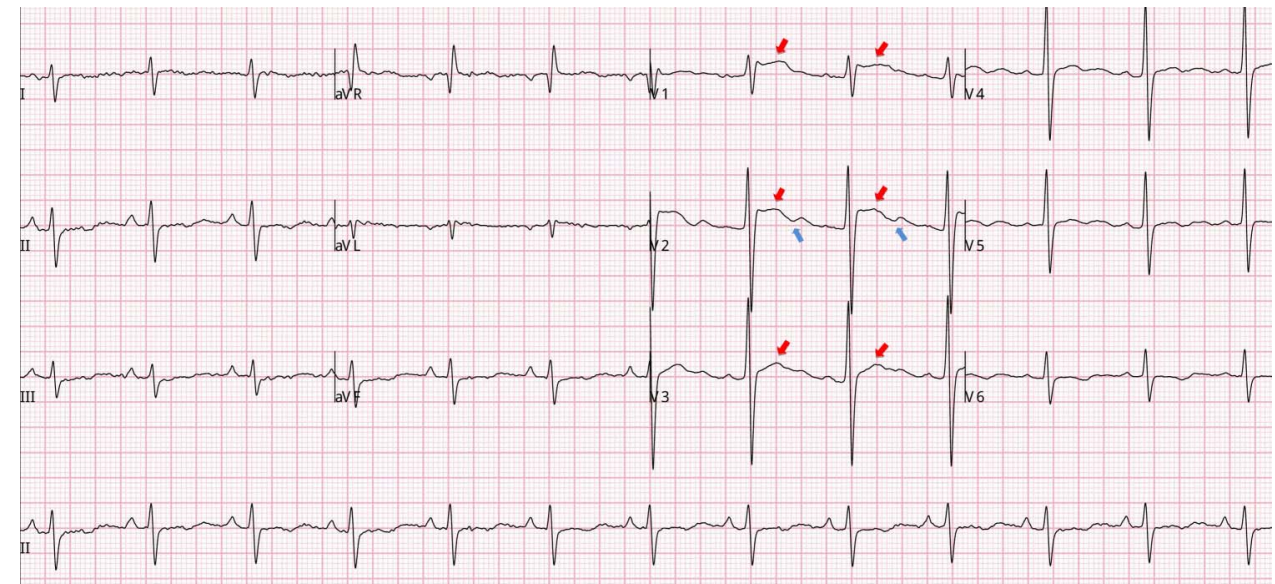

Figure 3 Twelve-lead ECG showing saddleback type ST elevation (red arrows) in leads V1-V3 and biphasic T wave (blue arrows).

Though genetic mutation is seen in almost half the cases and helps in diagnosis, it has no role in risk stratification in patients with $\mathrm{BrS} .{ }^{2}$ Use of an implantable cardioverter defibrillator is the only proven therapy to prevent SCD. ${ }^{4}$

Antiarrhythmic drugs have not been uniformly recommended and no large randomised prospective study is available looking at the effectiveness of antiarrhythmic drug therapy in BrS. Belhassen $e t a l^{5}$ have shown that quinidine effectively prevented induction of ventricular tachycardia/VF in $96 \%$ of patients. Isoproterenol, sometimes in combination with quinidine, has also been shown to be effective in normalising ST segment elevation in patients with $\mathrm{BrS}$ and in controlling electrical storms, particularly in children. ${ }^{6}$

Our patient developed haemodynamically unstable polymorphic ventricular tachycardia, resulting in decreased cerebral perfusion causing hypoxic ischaemic encephalopathy. Though arrhythmic episodes in BrS are more common from 12:00 to 06:00, it is interesting to note that, in our patient, the episode occurred around 09:00. Our patient was advised an implantable cardioverter defibrillator and his family was counselled regarding the need for genetic testing. Genetic testing in first degree relatives of patients with BrS may play a decisive role in who should take precautions in appropriate conditions and who should be followed. ${ }^{7}$

\section{Learning points}

- Recurrent unexplained syncope or presyncope may be the only presentation of Brugada syndrome in middle-aged men before developing sudden cardiac death.

- Brugada syndrome should be considered as a differential diagnosis in middle-aged men of Asian origin with unexplained syncope or presyncope.

- Careful scrutiny of ECG and enquiring about the history of sudden cardiac death among family members, are of utmost importance in the evaluation of syncope or presyncope, especially in young adults.

Contributors GCG, AGA and JRJ looked after the patient during his stay as an inpatient. All the authors contributed to the writing of the case report.

Competing interests None declared.

Patient consent Obtained.

Provenance and peer review Not commissioned; externally peer reviewed. 


\section{REFERENCES}

1 Brugada P, Brugada J. Right bundle branch block, persistent ST segment elevation and sudden cardiac death: a distinct clinical and electrocardiographic syndrome: a multicenter report. J Am Coll Cardiol 1992;20:1391-6.

2 Antzelevitch C, Brugada P, Borggrefe $M$, et al. Brugada syndrome: report of the second consensus conference: endorsed by the Heart Rhythm Society and the European Heart Rhythm Association. Circulation 2005;111:659-70.

3 Brugada J, Brugada R, Brugada P. Determinants of sudden cardiac death in individuals with the electrocardiographic pattern of Brugada syndrome and no previous cardiac arrest. Circulation 2003;108: 3092-6.

4 Shiue HC, Divakaran VG, Lakkis NM. A case of brugada syndrome presenting with incessant polymorphic ventricular tachycardia. Clin Cardiol 2010;33:E33-5.
5 Belhassen B, Viskin S, Fish R, et al. Effects of electrophysiologic-guided therapy with Class IA antiarrhythmic drugs on the long-term outcome of patients with idiopathic ventricular fibrillation with or without the Brugada syndrome. J Cardiovasc Electrophysiol 1999;10:1301.

6 Belhassen B, Viskin S, Antzelevitch C. The Brugada syndrome: is ICD the only therapeutic option. Pacing Clin Electrophysiol 2002;25:1634-40.

7 Ackerman MJ, Priori SG, Willems S, et al. HRS/EHRA expert consensus statement on the state of genetic testing for the channelopathies and cardiomyopathies: this document was developed as a partnership between the Heart Rhythm Society (HRS) and the European Heart Rhythm Association (EHRA). Heart Rhythm 2011;8:1308-39.

Copyright 2016 BMJ Publishing Group. All rights reserved. For permission to reuse any of this content visit http://group.bmj.com/group/rights-licensing/permissions.

BMJ Case Report Fellows may re-use this article for personal use and teaching without any further permission.

Become a Fellow of BMJ Case Reports today and you can:

- Submit as many cases as you like

- Enjoy fast sympathetic peer review and rapid publication of accepted articles

- Access all the published articles

- Re-use any of the published material for personal use and teaching without further permission

For information on Institutional Fellowships contact consortiasales@bmjgroup.com

Visit casereports.bmj.com for more articles like this and to become a Fellow 